\title{
Nitriding of Medium Carbon Ferromanganese Alloy in Gas Solid Reaction
}

\author{
Saeed N. Ghali \\ Central Metallurgical Research \& Development Institute, CMRDI \\ P. O. Box 87 Helwan, Egypt \\ www.cmrdi.sci.eg, Email: a3708052@yahoo.com
}

\begin{abstract}
Nitriding process of medium carbon ferromanganese was carried out in the solid state, on lab and bench scale at temperature range 1023-1323 K using different nitrogen and hydrogen pressures. The influence of $\mathrm{H}_{2} / \mathrm{N}_{2}$ gas ratio, temperature and time on nitriding process of fine (-2 $\mathrm{mm})$ medium carbon ferromanganese were investigated. Nitrogen content, in weight percent ranging from 2.1 to 9.7 could be obtained. The optimum temperature and time of nitriding process was found to be $1223 \mathrm{~K}$ and $21.6 \mathrm{ks}$ respectively. The results showed that nitrogen content is mainly depending on time and temperature of nitriding process. The comparison between results of lab and bench scale, at optimum conditions, showed good coincidence. At optimum conditions; $1223 \mathrm{~K}, 21.6 \mathrm{ks}$ and at 2/8 of $\mathrm{H}_{2} / \mathrm{N}_{2}$, nitrogen content of fine medium carbon ferromanganese was $9.5 \%$.
\end{abstract}

\section{INTRODUCTION}

Ferromanganese alloys are widely used as additive in steelmaking process. During crushing of ferromanganese alloy to suitable sizes to be directly used in steelmaking process, more than $5 \%$ of the alloy is produced in fine size. This fine size alloy must be retreated to be suitable for utilization. Due to the increased demand for nitrogen to replace nickel it is suggested to produce high nitrogen ferromanganese through nitrogenation- in solid state- of these fines [1-6].

On the bases of Mn-N phase diagram [7-8], the nitrogen pickup by solid manganese is much more than that by liquid one. Manganese combines with nitrogen to form different manganese nitrides. Zhukov found that manganese can be nitrided by nitrogen gas and the maximum nitrogen content in the product is not higher than $12-12.5 \%$ [9-10]. 
The alloy of manganese with nitrogen, containing 30 atomic percent of nitrogen, is stable on being heated in hydrogen up to $973 \mathrm{~K}$, while at $1273 \mathrm{~K}$ the content of nitrogen in the alloy decreases to 20 atomic percent. The longer time of nitriding process cause a slight increase in nitrogen pickup at temperature below to $1223 \mathrm{~K}$ [11-12].

It was earlier reported that the interstitial phases existed in the system $\mathrm{Mn}-\mathrm{N}$, namely, $\mathrm{Mn}_{4} \mathrm{~N}$,

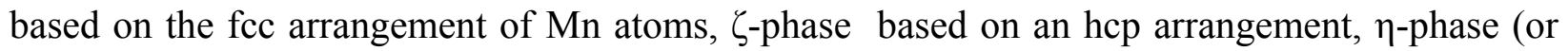
$\mathrm{Mn}_{6} \mathrm{~N}_{4}$ ) based on a tetragonal arrangement, and $\theta$-phase (or $\mathrm{Mn}_{6} \mathrm{~N}_{5}$ ) based on fct arrangement [7,13-15].

The heat of formation $(-\Delta \mathrm{H})$ of manganese nitrides are $+39.9 \mathrm{kcal} / \mathrm{mole}$ for $\mathrm{Mn}_{4} \mathrm{~N},+57.8$ $\mathrm{kcal} / \mathrm{mole}$ for $\mathrm{Mn}_{5} \mathrm{~N}_{2}\left(\mathrm{Mn}_{2} \mathrm{~N}\right)$ and $+45.8 \mathrm{kcal} / \mathrm{mole}$ for $\mathrm{Mn}_{3} \mathrm{~N}_{2}[9,11,16]$.

The overall gas-solid metal reaction (nitrogen-medium carbon ferromanganese) which involves adsorption - desorption mechanism can be described as follows [17]:

$N_{2 g a s} \leftrightarrow N_{2 i} \quad$ mass transfer in the gaseous phase

$N_{2 i} \leftrightarrow N_{2 a d} \quad$ adsorption of $\mathrm{N}_{2}$ gas on ferromanganese surface

$N_{2 a d} \leftrightarrow 2 N_{a d} \quad$ dissociation of $\mathrm{N}_{2}$ gas molecules

$N_{a d} \leftrightarrow N_{i .}$

$N_{i .} \leftrightarrow N_{\text {bulk }} \quad$ mass transfer in solid medium carbon ferromanganese

Where

$\mathrm{N}_{2}$ : Free nitrogen gas molecules

$\mathrm{N}_{2 \mathrm{i}}$ : Nitrogen gas molecules closest to ferromanganese surface

$\mathrm{N}_{2 \mathrm{ad}}$ : Adsorbed nitrogen gas molecule on the surface of ferromanganese

$\mathrm{N}_{\mathrm{ad}}$ : Adsorbed nitrogen atom on the surface of ferromanganese

$\mathrm{N}_{\mathrm{i}}$ : Nitrogen combined with manganese at the surface of ferromanganese

$\mathrm{N}_{\text {bulk }}$ : Nitrogen combined with manganese at the bulk of ferromanganese

Therefore, the absorption of nitrogen gas by the solid ferromanganese pass through stages: $\mathrm{N}_{2}$ gas transfer to the surface of ferromanganese, adsorption of $\mathrm{N}_{2}$ gas molecules on the FeMn surface, dissociation of the nitrogen gas molecules into atoms and diffusion of the adsorbed atoms from the surface of the metal into the bulk of solid ferromanganese particles.

\section{EXPERIMENTAL}

Nitriding process of medium carbon ferromanganese in the solid state was carried out. The chemical composition of medium carbon ferromanganese used in the experimental work was $1.2 \% \mathrm{C}, 87.60 \% \mathrm{Mn}$, and $0.01 \% \mathrm{Si}$. Experiments were carried out on laboratory and bench scale 
using $35 \mathrm{gm}$ and $500 \mathrm{gm}$ respectively of fine medium carbon ferromanganese particles (- $2 \mathrm{~mm}$ size). Nitrogen gas was used as source of nitrogen. Fig.1 shows a schematic diagram of laboratory nitriding system. The system mainly consists of two units. The first unit is the purification unit. The purification unit purifies gases from oxygen using tube furnace containing copper turning - heated to $843 \mathrm{~K}$, and moisture using 4 drying towers filled by anhydrous calcium chloride and magnesium perchlorate before entering the nitriding unit. The tube furnace for oxygen removal is placed in-between two couples of drying towers. The second unit is nitriding unit. The nitriding unit consists of an electric resistance tube furnace, with maximum temperature $1473 \mathrm{~K}$, and a heat resistant steel reaction tube ending with two valves, one on each side. At the outlet of the reaction tube a pressure gauge is connected.

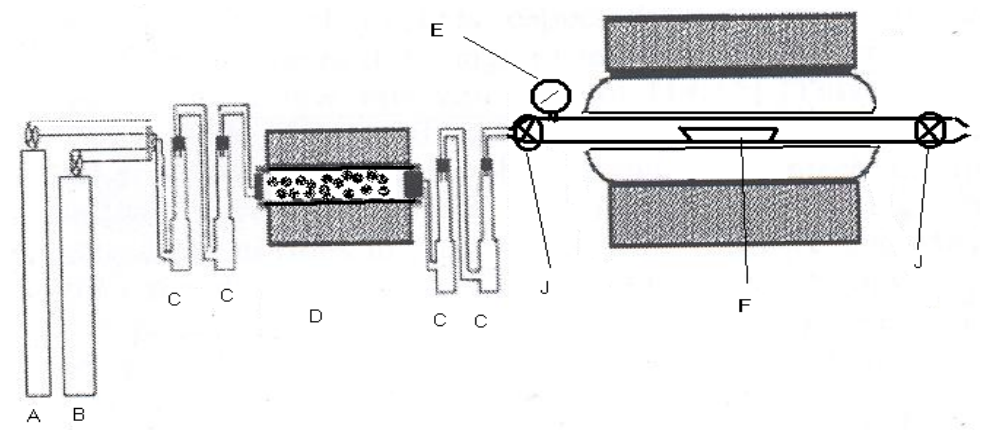

Fig. 1: Schematic diagram of nitriding apparatus
A: $\mathrm{H}_{2}$ gas cylinder
B: $\mathrm{N}_{2}$ gas cylinder
$\mathrm{C}:$ Dryers
D: Tube furnace with cupper turnings
$\mathrm{J}:$ Valves
E: Pressure gauge
F : Boat containing sample

In laboratory experiments, the fine ferromanganese particles were placed into an alumina boat which was introduced into the hot zone of the nitriding furnace. The furnace at first was tested for gas leakage then the nitriding unit was flushed gently with hydrogen. The outlet valve was then closed and the gases $\left(\mathrm{H}_{2} \& \mathrm{~N}_{2}\right)$ were injected into the nitriding unit until the required pressure of gases was reached. The temperature was raised gradually to the required temperature. The nitriding process continued for the selected time. The furnace was, then switched off and the outlet valve was opened gradually to reach the normal pressure and it was closed again and hydrogen gas was introduced in the unit and the nitrided sample was left in the furnace to cool to room temperature. Then the outlet valve was opened gradually to remove hydrogen.

Nitriding process was carried out at $1223 \mathrm{~K}$ for $21.6 \mathrm{ks}$ using different $\mathrm{H}_{2} / \mathrm{N}_{2}$ gas ratio. At the same time a series of these laboratory scale nitriding experiments were made at different temperatures ranging from $1023 \mathrm{~K}$ to $1323 \mathrm{~K}$, at time range $7.2-28.8 \mathrm{ks}$ using gas pressure 10 
bars containing partial pressures of $\mathrm{H}_{2}$ and $\mathrm{N}_{2} 0.2$ \& 0.8 respectively. The phases of nitrided samples were examined by X-ray Diffraction technique. The nitrogen content of each sample was determined by kejldahl apparatus [18]. Each sample was analyzed three times and the average value of nitrogen content was considered.

The apparatus of nitriding fine ferromanganese on bench scale is similar to the laboratory one. Only, the nitriding unit has larger volume. By the end of laboratory experiments, bench scale experiments were carried out using the optimum condition resulting from laboratory experiments.

\section{RESULTS AND DISCUSSION}

The nitrogen pickup of the laboratory experiments at different conditions is listed in Table (1). Nitrogen pickup of fine medium carbon ferromanganese increases from $6.5 \%$ to $9.5 \%$ when $\mathrm{H}_{2} / \mathrm{N}_{2}$ gas ratio increases from $1 / 16$ to $1 / 4$. as shown in Fig. (2). Further increase $\mathrm{H}_{2} / \mathrm{N}_{2}$ gas ratio, the nitrogen pick up decreases from $9.5 \%$ to $3.2 \%$.

Table (1): Nitrogen content of medium carbon ferromanganese at different time and temperature.

\begin{tabular}{|c|c|c|c|c|c|c|c|c|c|}
\hline & \multicolumn{9}{|c|}{$\mathrm{N} \%$ (wt.\%) } \\
\hline \multirow{2}{*}{$\begin{array}{l}\mathrm{H}_{2} / \mathrm{N}_{2} \text { Ratio } \\
\text { Temperature, } \mathrm{K}\end{array}$} & $2 \mathrm{H}_{2}$ & $2 \mathrm{H}_{2}$ & $2 \mathrm{H}_{2}$ & \multicolumn{4}{|c|}{$2 \mathrm{H}_{2}+8 \mathrm{~N}_{2}$} & $1 \mathrm{H}_{2}+$ & $0.5 \mathrm{H}_{2}$ \\
\hline & \multicolumn{3}{|c|}{1223} & 1023 & 1123 & 1223 & 1323 & $1223 \mathrm{~K}$ & $1223 \mathrm{~K}$ \\
\hline \multicolumn{10}{|l|}{ Time, ks } \\
\hline 7.2 & & & & 2.1 & 3.9 & 6.6 & 3.7 & & \\
\hline 14.4 & & & & 2.9 & 5.2 & 8.1 & 5.1 & & \\
\hline 21.6 & 3.2 & 4.6 & 6.4 & 3.4 & 5.9 & 9.5 & 5.8 & 8.4 & 6.5 \\
\hline 28.8 & & & & 3.5 & 6.1 & 9.7 & 5.9 & & \\
\hline
\end{tabular}

Hydrogen has two opposite effects. The first one, the presence of hydrogen gas in gas mixture reacts with carbon of medium carbon ferromanganese alloy [19]. This leads to increasing the diffusion of nitrogen into bulk of alloy. Also, hydrogen retards the formation of oxides (iron and manganese oxides).

On the other hand, as $\mathrm{H}_{2} / \mathrm{N}_{2}$ gas ratio increases more than $1 / 4$ the nitrogen pick up decreases as a result of dilution of the nitrogen i.e. decrease of the partial pressure of nitrogen I.e. decreasing the $\mathrm{N}_{2}$ partial pressure decreases the collision of nitrogen with the fine medium carbon ferromanganese particles and therefore nitrogen molecules which will be adsorbed on the 
particles surface decreases and the combination between nitrogen \& manganese will decreases consequently.

Fig.(3) illustrates the effect of temperature on the nitrogen content of medium carbon ferromanganese using 10 bar gas mixture of $2 \mathrm{H}_{2}$ bar and $8 \mathrm{~N}_{2}$ bar. It is clear from this figure that the nitrogen pickup increases as temperature of reaction increases up to $1223 \mathrm{~K}$. At higher temperatures above $1223 \mathrm{~K}$ up to $1323 \mathrm{~K}$, the nitrogen pickup decreases.

The first increase can be attributed to that the velocity of nitrogen gas increases. This cause that the number of nitrogen molecules which have activation energy increase and hence the probability of reaction increases. This leads to the increase of the nitrogen content.

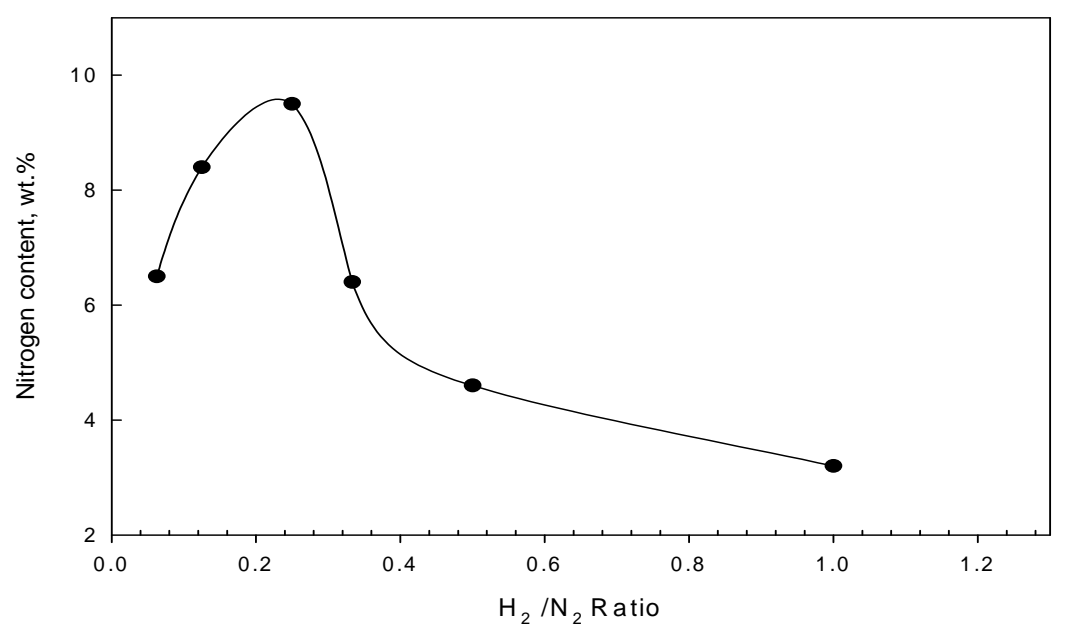

Fig. 2: The variation of nitrogen pickup with different $\mathrm{H}_{2} / \mathrm{N}_{2}$ Ratio

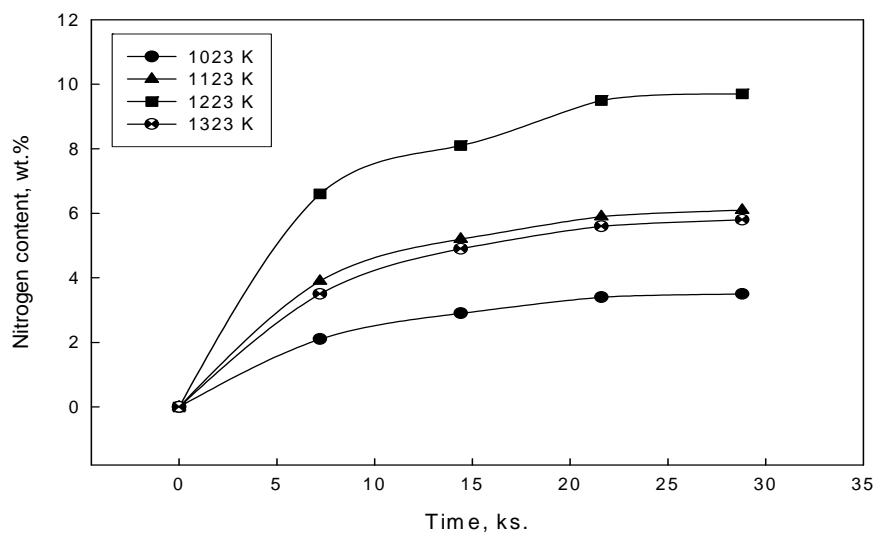

Fig. 3: Effect of temperature on nitrogen pickup of medium carbon ferromanganese at different time 
Nitrogen pickup decreases at higher temperature $(1323 \mathrm{~K})$ seems be due to the decomposition of manganese nitride $\left(\mathrm{Mn}_{2} \mathrm{~N}\right)$ into lower nitrogen manganese nitrides $\mathrm{Mn}_{4} \mathrm{~N}$ as it is clear from XRD results illustrated in Fig.(4). The dissociation process of high nitrogen manganese nitrides into lower nitrogen manganese nitrides enhanced at this temperature range to form a solid solution with low nitrogen content [20-21]. These results also agree with the results obtained by Hndsbedt and Olsen who reported that the decomposition of formed nitrides ( $\mathrm{Mn}, \mathrm{Fe}) \mathrm{N}$ takes place at approximately $1273 \mathrm{~K}$ [22].

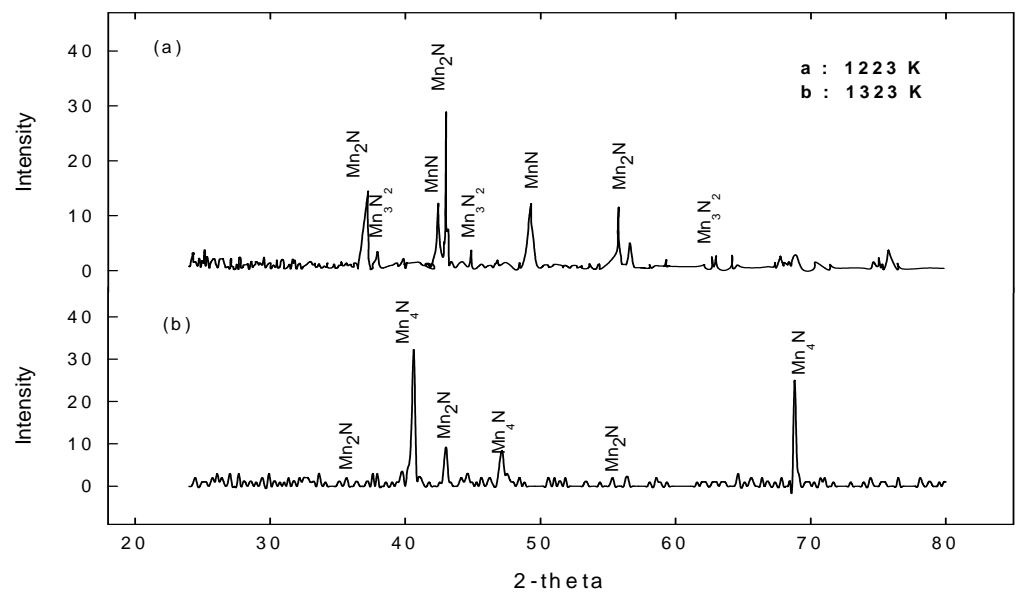

Fig. 4: XRD of fine ferromanganese nitrogen after nitriding process at $1223 \mathrm{~K}$, and $1323 \mathrm{~K}$.

The rate of nitrogen pickup at different temperatures $(1023 \mathrm{~K}, 1123 \mathrm{~K}, 1223 \mathrm{~K}$ and $1323 \mathrm{~K})$ is greatest at first time, and then slightly increases with time to reach leveling after about $21.6 \mathrm{ks}$ as shown in Fig.(3). This behavior may be attributed to the beginning of nitriding process, the surface of fine ferromanganese was free i.e. no nitrogen adsorbed. This leads to nitrogen pickup by higher rate. By the time, the vacant free (not adsorbed) decrease and hence the nitriding rate decreases.

The nitrogen diffusion flow can be expressed by the first order equation (6).

$\frac{d N}{d t}=\alpha\left(N_{\text {eq. }}-N_{v}\right)$

Where $\mathrm{dN} / \mathrm{dt}$ is the diffusion flow, $\alpha$ is the nitrogen transfer coefficient into the ferromanganese alloy, $\mathrm{N}_{\text {eq. }}$ is the nitrogen concentration in equilibrium with the gaseous phase and $\mathrm{N}_{\mathrm{v}}$ is the nitrogen concentration within the volume of the ferromanganese alloy. 
This equation indicates that the gas nitriding process of ferromanganese is controlled by the solid state diffusion of nitrogen in the ferroalloy, and it also shows that nitrogen adsorption becomes retarded as the nitrogen content in the ferromanganese alloy increases until it reaches $\mathrm{N}_{\text {eq }}$ [23-24] The result of bench scale experiment is in good agreement with the laboratory scale at optimum conditions. The nitrogen content -in bench scale- was $8.9 \%$, when the nitrogen $\&$ hydrogen partial pressures were 8 and 2 respectively at $1223 \mathrm{~K}$ after nitriding process for $21.6 \mathrm{ks}$.

\section{CONCLUSIONS}

From the experimental results, one can be concluded the following:

- The nitrogen content in medium carbon ferromanganese increases by increasing time at temperature range $1023 \mathrm{~K}-1323 \mathrm{~K}$ when gas mixture $\mathrm{N}_{2}$ and $\mathrm{H}_{2}$ are 8 \& 2 bars respectively.

- Nitrogen pick up reaches to leveling after $21.6 \mathrm{ks}$ at temperature range $1023 \mathrm{~K}-1323 \mathrm{~K}$.

- The increase in temperature in range $1023 \mathrm{k}$ to $1223 \mathrm{~K}$ has a positive significant effect in nitrogen pick up, due to increase the probability of activated nitrogen molecules to form manganese nitrides.

- The nitrogen pick up decreases by increasing temperatures from $1223 \mathrm{~K}$ to $1323 \mathrm{~K}$, due to the dissociation of manganese nitrides from high nitrogen to lower nitrogen manganese nitrides.

- Optimum $\mathrm{H}_{2} / \mathrm{N}_{2}$ gas ratio in nitriding process of low-carbon ferromanganese is $1 / 4$

- The results of pilot scale are in good agreement of laboratory scale at optimum condition.

\section{REFERENCES}

1. EUI-JUN KIM, BYUNG-DON YOU, and JONG-PAK " nitrogen solubility in liquid manganese and ferromanganese alloys" Metallurgical and Materials transactions B, Aug. 2001, Vol. 32B, pp 659-668.

2. D.S. Kozak and L.R Matricardi: Iron Steelmaker, 1981. Vol.8 (4), pp.28-31

3. E. Schurmann, A. Ender, E. Hofiken, H. Litterscheld, and C.H. Schutzi Stov Eisen. 1993, vol 113, pp. 77-82

4. W. Dresler: Can. Metall. Q. 1989, vol. 28, pp. 109-115.

5. B. D. You, K.Y. Park, J.J. Pak, and J. W. Han: Mater., 1999, vol5, pp. 395-399.

6. B. D. You J. W. Han and J.J. Pak: Steel Res. 2000, vol 71(1-2),pp.22-26.

7. N. A. Gokcen The Mn-N System [J]. Bulletin of Alloy Phase Diagrams, 1990, 11(1), 33.

8. C. Qiu, A F. Guillermet Predicative Approach to the Entropy of Manganese Nitrides and Calculation of the Mn-N Phase Diagram [J]. Z Metallkd, 1993, 84(1), 11.

9. Metal phase diagram or binary phase diagram " nitrogen and manganese"pp.573-578.

10. Zhukov, I.I. - Zhurnal Russkogo Fiziko - Khimicheskogo Obshchestva, vol. 40; 457. 1908; vol.42;40. 1910; Izv. Sektora Fiziko-Khimicheskogo Analiza, 3(1): 14. 1926. 
11. M. P. Slavinskii, Fiziko-Khimicheskie svoistva elementrov (physicochemical properties of elements), p. 549.,-Metallurgizdat. 1952.

12. Zwicker, U. -Zeitschr, Metallkunde, 1951, 42(9): 274.

13. Zhang Jin-Zhu, XU Chu-Shao, Zhao Yue -Ping" Kinetics of nitrogen diffusion in granular manganese" Journal of iron and steel research, International. 2008, 15(1), pp. 85-88

14. M. Hansen, K. Anderko Constitution of binary alloys[M], New York: McGraw Hill, 1958.

15. F. Lihl, P. Ettmayer, Kutzelnigg A. The System Manganese Nitrogen [J]. Z Metallkd, $1962,53,715$.

16. L. L. Quil, The chemistry and Metallurgy of Miscellaneous Materials; Thermodnamics. McGraw Hill Book Company, Inc. New York-Toronto-London. 1950.

17. V. Grigoryan, L Belyanchikov and A. Stomakhin, " theotetical principles of electric steelmaking", 1979, Mir Publisher, Moscow.

18. A. Vogel, A Textbook of Quantitative Inorganic Analysis Including Elementary Instrumental Analysis, Woolwich Polytechnic, London, 1992.

19. A Ahmed, T. Mattar, A. Fathy, H. EL_Faramawy and M. Eissa. " Solid state nitrogen of high and medium carbon ferromanganese", Canadian Metallurgical Quarterly, 2006, No. 4,Vol. 45, pp. 493-498,

20. Phase diagrams of binary iron alloys, 1993, Okamoto, H., (ed): ASM International, The Material Information Society, USA.

21. T. B. Mossalski, et al "Binary alloy phase diagrams", $2^{\text {nd }}$ edition, 1996, , (eds), vol. 3, ASM International, The Material Information Society, USA, 1996

22. L. Hunsbedt and S.E. Olsen, " nitriding of ferromanganese", Proc. Of the $51^{\text {st }}$ Electr. Furn. Conf. 1993, Warrendale, Commonwealth, November 7-10, vol. c, pp. 129-136.

23. S. Filipov, The theory of metallurgical process, 1979, Mir publisher, Moscow.

24. L. Torchane, et al. "Control of Iron Nitride Layers Growth Kinetics in the Binary Fe-N system" Jour. Metall. Trans., 1996, 27A(7), 1823. 